\title{
EDUCAÇÃO AMBIENTAL NAS ESCOLAS PÚBLICAS: UM ESTUDO SOBRE A REDE MUNICIPAL DE ENSINO DE TERESÓPOLIS (RJ)
}

Luciano Coelho de Magalhães ${ }^{1}$

Resumo: Este artigo busca comunicar uma pesquisa de mestrado que abordou a inserção da Educação Ambiental (EA) na rede pública municipal de ensino de Teresópolis-RJ. A partir da aplicação de um questionário, foi possível não só diagnosticar a presença da EA nas escolas, mas suas ações educativas ambientais. Os principais resultados desta investigação, interpretados a partir da vertente crítica da EA brasileira, revelaram que o direito à $E A$, dever do poder público, é em Teresópolis um privilégio de poucos. Sobre a EA que se faz naquela rede, identificamos o predomínio de práticas inspiradas nas concepções conservadora e pragmática da EA no Brasil e, portanto, alheias a urgente transformação da realidade socioambiental local.

Palavras-chave: Educação Ambiental; Direito à Educação Ambiental; Rede Pública Municipal de Ensino de Teresópolis. 


\section{Introdução}

Este artigo busca comunicar uma pesquisa de mestrado. Tal pesquisa - desenvolvida entre os anos de 2012 e 2014, no âmbito do Programa de PósGraduação em Educação da Universidade Católica de Petrópolis - aborda a inserção da Educação Ambiental na rede pública municipal de ensino de Teresópolis (município localizado na Região Serrana do Estado do Rio de Janeiro).

A escolha do tema e do recorte desta investigação tem relação com nosso exercício profissional. Atuando como professor de história na mencionada rede pública de educação básica desde o ano de 2008, desenvolvemos em 2010, uma ação educativa intitulada "Projeto História na Rua: Um encontro ativo e crítico com a história de Teresópolis nas ruas da cidade a partir de alguns dos seus 'personagens de bronze'”. Após sua divulgação na rede - através de uma publicação da Secretaria Municipal de Educação de Teresópolis - recebemos um convite para compor a equipe encarregada de aperfeiçoar as apostilas do projeto "Cenário Verde"2 (Edição 2011). Nosso aceite àquele convite marcaria o início de nossa caminhada pelo campo da Educação Ambiental.

Em meio à realização daquele trabalho, a Região Serrana do Estado do Rio de Janeiro viveu um terrível pesadelo, noticiado assim pelo jornal "O Globo" (Caderno Especial - "Tragédia na Serra") do dia 13 de janeiro de 2011:

A Região Serrana do Rio amanheceu ontem mergulhada em lágrimas. Castigadas por chuvas torrenciais durante a noite de anteontem e a madrugada de ontem, as cidades de Nova Friburgo, Teresópolis e Petrópolis contabilizaram 271 mortos, número que pode aumentar, já que ainda há pessoas desaparecidas sob montes de lama e escombros.

Poucas semanas depois, apenas em Teresópolis, o número oficial de mortos chegava a 392.

Considerando a ocorrência neste município do maior desastre "natural" da história do país não é difícil justificar a importância social e educacional do tema proposto em nossa pesquisa e muito menos afirmar a necessidade do atributo "ambiental" à educação ali ofertada.

Talvez por esta razão, enquanto a cidade ainda contava seus mortos, o chefe do executivo local, sancionava a Lei Municipal n. 3.017/2011, que instituiu a Política Municipal de Educação Ambiental de Teresópolis (TERESÓPOLIS, 2011).

2 A Secretaria Municipal de Educação, em parceria com o Parque Nacional da Serra dos Órgãos desenvolve desde 2009 o projeto "Cenário Verde", trata-se de uma proposta de visitação àquela Unidade de Conservação de Proteção Integral. Prevista na metodologia encontra-se uma visita de campo por parte dos professores inscritos e a distribuição de apostilas contendo sugestões de conteúdos e atividades relacionadas às diferentes disciplinas.

Revbea, São Paulo, V. 11, № 2: 11-21, 2016. 
Nascido no contexto em que as enormes mazelas socioambientais de Teresópolis foram expostas sem pudor por aquela tragédia, nosso estudo buscou identificar as políticas e as práticas de Educação Ambiental desenvolvidas nos estabelecimentos de ensino que constituíam a rede pública municipal de ensino.

Inicialmente, através da Internet, procedemos ao levantamento dos marcos legais da Educação Ambiental de Teresópolis. Concomitantemente a este primeiro passo contatamos, em meados de 2012, o coordenador de meio ambiente da Secretaria Municipal de Meio Ambiente e a chefe da divisão de educação para o campo, da Secretaria Municipal de Educação (SME) de Teresópolis, ambos responsáveis pela Educação Ambiental em suas respectivas secretarias municipais.

Ao buscarmos na Secretaria de Meio Ambiente informações sobre a implementação da Política Municipal de Educação Ambiental (TERESÓPOLIS, 2011), fomos informados que, em razão da crise política ${ }^{3}$ que se abateu sobre a cidade após a catástrofe, a referida política ainda não havia sido efetivada.

Se à primeira vista tal política municipal (TERESÓPOLIS, 2011) pareceu indicar uma mudança de rumo, o início de uma transformação da realidade local a partir da Educação Ambiental, atualmente tendemos a associar sua criação ao interesse do prefeito Jorge Mário - cuja imagem havia sido duramente atingida pela catástrofe - de ter um palanque eleitoral ${ }^{4}$. Talvez por isso, a Política Municipal de Educação Ambiental de Teresópolis (TERESÓPOLIS, 2011) não tenha saído do papel até hoje.

Na SME, inspirados pelo projeto "Pegada Ambiental" (Nuredam/Uerj) ${ }^{5}$, expomos nosso interesse de realizar uma espécie de diagnóstico das ações educativas ambientais desenvolvidas na rede pública municipal de Teresópolis.

\footnotetext{
${ }^{3}$ Após a tragédia de 12/01/2011 denúncias de desvios de recursos públicos destinados à reconstrução da cidade sacudiram o município levando a um clima de profunda indignação. Passeatas e até o apedrejamento da Câmara de Vereadores deram o tom da insatisfação local. A decisão da Câmara Municipal de afastar o prefeito por 90 dias (tomada em 02/08/2011) foi seguida pelos seguintes episódios: No dia 01/11/2011 o prefeito, Jorge Mário Sedlacek, eleito por cerca de 42 mil votos no pleito de 2008, foi cassado, por unanimidade, pela Câmara dos Vereadores. Em 05/11/2011, o então vice-prefeito Roberto Pinto "Robertão" foi oficialmente empossado. Dois dias depois de assumir o cargo "Robertão", morreu vítima de um infarto fulminante. O presidente da Câmara, Arlei de Oliveira Rosa, assumiu interinamente o cargo de prefeito. No dia 06/12/2011 o Tribunal Regional Eleitoral do Rio de Janeiro determinou a realização de uma nova eleição para prefeito e vice. Dias depois, o pleito marcado para o dia 05/02/2012, foi suspenso pelo Tribunal Superior Eleitoral.
}

${ }^{4}$ Em 6 de junho de 2011, um dia após a assinatura simbólica da Lei Municipal n. 3.017/2011 que instituiu a Política Municipal de Educação Ambiental de Teresópolis (TERESÓPOLIS, 2011), o sítio oficial da Prefeitura noticiava o evento que marcou o Dia Mundial do Meio Ambiente em Teresópolis: "Durante o evento, o Prefeito Jorge Mario destacou as principais conquistas ambientais garantidas pelo seu governo para o município, [...]. 'O meio ambiente é o patrimônio maior que uma sociedade pode ter. Nosso compromisso é ter políticas públicas que façam com que as nossas florestas, encostas e rios sejam preservados e recuperados. Esse é o nosso compromisso, essa é a nossa marca de governo', assinalou Jorge Mario, [..]." Disponível em: <http://teresopolis.rj.web.br.com/noticias/indexfull.php?sec_not_id=1317>. Acesso em: 13 mai. 2013.

${ }^{5}$ Desenvolvido pela Secretaria de Estado de Educação do Rio de Janeiro (Seeduc) em parceria com o Núcleo de Referência em Educação Ambiental da Universidade do Estado do Rio de Janeiro Revbea, São Paulo, V. 11, № 2: 11-21, 2016. 
A generosa acolhida e o irrestrito apoio que ali recebemos precipitou, visto a proximidade das eleições municipais, agendada para outubro de 2012 , o desenvolvimento da pesquisa nas escolas. Assim, pulando etapas, partimos imediatamente para a montagem do nosso instrumento de coleta de dados (questionário). Ressalta-se que esta opção metodológica se apoiou em outros estudos sobre a inserção da Educação Ambiental nas escolas brasileiras de educação básica (TRAJBER; MENDONÇA, 2006; LAMOSA, 2010).

Tendo como base o questionário da pesquisa - "O que fazem as escolas que dizem que fazem Educação Ambiental?" (TRAJBER; MENDONÇA, 2006) e o questionário do projeto "Pegada Ambiental" (Nuredam/Uerj) construímos nosso instrumento de pesquisa.

Após sua reprodução o entregamos a chefe da divisão de educação para o campo da SME, que os encaminhou a todos os 94 estabelecimentos de ensino pertencentes ao poder público municipal. Solicitamos que o questionário encaminhado as escolas fosse respondido pelos diretores e orientadores pedagógicos, após consulta aos docentes.

Dos 50 questionários que retornaram, 33 vieram de escolas localizadas na zona urbana e 17 na zona rural. Nestas duas regiões havia respectivamente 61 e 33 instituições de ensino da rede municipal. Das 33 escolas urbanas que devolveram o questionário respondido, 24 afirmaram que desenvolviam atividades de Educação Ambiental. Das 17 escolas rurais, 14 declaram o mesmo.

Os principais resultados de nossa pesquisa nas escolas, interpretados a partir da vertente crítica da Educação Ambiental brasileira (LAYRARGUES; LIMA, 2011), são apresentadas na próxima seção.

\section{Educação Ambiental na rede pública municipal de Teresópolis (RJ): por uma Educação Ambiental crítica}

Uma de nossas primeiras questões buscou saber o que provocou o começo do trabalho educativo ambiental nas escolas ("Programa Parâmetros em Ação: meio ambiente na escola"; "Políticas e programas Nacional, Estadual e/ou Municipal de EA"; "Projeto de empresa"; "Iniciativa de um professor ou de um grupo de professores" etc.). Apenas 10 dos nossos 37 respondentes 6 assinalaram nesta questão uma única alternativa de resposta. Destes 10 respondentes, 5 marcaram a opção "Outros", anotando em seguida as seguintes observações: [1] "Entendemos que a criança pequena está em formação da personalidade. Este é o momento de incutir valores, que

(Nuredam/Uerj) o projeto "Pegada Ambiental" visa a criação de um instrumento de avaliação das atividades de educação ambiental empreendidas pelas unidades escolares da rede estadual de ensino. Cf: PEGADA AMBIENTAL". Disponível em: <http://www.rj.gov.br/web/seeduc/exibeconteudo?article-id=969697>. Acesso em: 03 out. 2013.

6 Embora 38 respondentes tenham afirmado que em suas escolas havia educação ambiental, um deles não respondeu a questão sobre o que provocou o início do trabalho com educação ambiental. Ressaltamos que tal fato também foi verificado em outras questões, com este e outros respondentes.

Revbea, São Paulo, V. 11, № 2: 11-21, 2016. 
devidamente trabalhados, permanecerão durante sua vida" (Questionário n. 6). [2] "Iniciativa da equipe" (Questionário n. 7). [3] "Por compreender a relevância do tema. (Questionário n. 10). [4] "Pela urgência do tema e pela sua importância, visto que desde a tenra idade as crianças necessitam de desenvolver essa consciência. (Questionário n. 27). [5] "Catástrofe de 2011" (Questionário n. 32).

Destaca-se nestas observações sobre o que provocou o começo do trabalho educativo ambiental nas escolas da rede pública municipal de Teresópolis, a ausência de referências institucionais, provenientes de instâncias públicas, programas e/ou projetos governamentais, prevalecendo, ao menos nestes casos, as percepções e as ações individualizadas, ou quando muito de uma "equipe" isolada.

Dos outros 5 respondentes que, nesta mesma questão, também marcaram uma única alternativa de resposta, 2 assinalaram a opção: "Iniciativa de um professor ou de um grupo de professores". Se considerarmos o total de respondentes (37) independentemente da quantidade de opção de respostas registradas temos que esta última alternativa ("Iniciativa de um professor ou de um grupo de professores") foi assinalada por 19 destes.

Tal resultado parece revelar uma tendência no desenvolvimento da Educação Ambiental na rede pública municipal de ensino de Teresópolis onde faz quem quer o que pode, como pode e sabe, tendência que se contrapõem radicalmente ao que determina a Lei, que, ao transformar a Educação Ambiental em um direito de todos (BRASIL, 1999), incumbiu ao poder público o dever de assegurá-la (BRASIL, 1999).

Em Teresópolis chama atenção o reduzido número de respondentes que atribuíram o começo do trabalho de Educação Ambiental em suas escolas a ação (via projetos) de empresas - apenas 4 em um universo de 37. Se considerássemos que outras 12 escolas da rede pública municipal de Teresópolis declaram não desenvolver nenhuma atividade de Educação Ambiental, concluiríamos na contramão de Lamosa (2010, p. 22) que os projetos de Educação Ambiental das empresas estão cada vez menos presentes nos estabelecimentos de ensino que compõe a referida rede pública de educação.

Quando estimulados a citarem o(s) meio(s) pelo(s) qual(is) a Educação Ambiental (EA) era desenvolvida, 19 dos 23 respondentes da zona urbana assinalaram a opção "projetos" (4 indicaram os "projetos" como a única estratégia de desenvolvimento da EA em suas escolas). Na zona rural 9 dos 14 respondentes também registraram a opção "projetos" (em 3 destes estabelecimentos de ensino localizados na zona rural os "projetos" eram o único meio pelo qual a EA era desenvolvida). Dos 19 respondentes da zona urbana que assinalaram a opção "projetos", 9 também marcaram a seguinte alternativa: "Inserção transversal integrando conteúdos de várias disciplinas". $\mathrm{Na}$ zona rural, esta última opção foi assinalada por 8 dos 14 respondentes. 
Em seu estudo de caso desenvolvido entre os anos de 2009 e 2010, em 25 escolas da rede municipal de Teresópolis, Lamosa (2010) observa: "O meio mais utilizado para o trabalho com a EA nas escolas é o projeto, [...]" (LAMOSA, 2010, p. 119) acrescentando que:

Em Teresópolis, a maioria das escolas a iniciativa dos projetos parte da equipe de direção (100\%), e por um grupo de professores $(95,80 \%)$. As empresas estão presentes em quase metade das escolas $(43,40 \%)$ (LAMOSA, 2010, p. 119).

Comparando estes últimos resultados do estudo de Lamosa (2010) com os dados da nossa pesquisa constatamos uma tendência de queda acentuada na influência das empresas sobre os projetos de Educação Ambiental desenvolvidos pelas escolas $(-10 \%)$ e pouco significativa em relação à atuação da equipe da direção $(-3,2 \%)$.

Por outro lado, observamos uma clara tendência de crescimento das iniciativas dos professores, especialmente das proposições de um único docente. Se na pesquisa de Lamosa (2010) as ações individuais representavam apenas 2,2\%, em nossa pesquisa este percentual alcançou $11,12 \%$. Quanto às iniciativas dos grupos de professores verificamos um aumento de 4,2\% em relação à pesquisa de Lamosa (2010).

Ainda no tocante a influência das empresas, indagamos sobre o envolvimento das mesmas nos projetos de Educação Ambiental (EA) desenvolvidos pelas escolas. Na zona urbana, 11 dos 17 respondentes afirmaram que as empresas não estavam envolvidas nas ações de EA implementadas em suas escolas. Na zona rural, 7 dos 10 respondentes declararam o mesmo. Vale mencionar que na pesquisa realizada por Lamosa (2010), 43,44\% dos entrevistados disseram que as empresas não tinham qualquer ligação com seus projetos de EA. O resultado desta questão (sobre os atores envolvidos nos projetos de EA) confirmou a tendência de queda da influência das empresas nos projetos de EA desenvolvidos pelas escolas da rede pública municipal de educação de Teresópolis.

Apesar de 56,60\% dos respondentes entrevistadas por Lamosa (2010) terem assinalado que a iniciativa da realização dos projetos de Educação Ambiental (EA) desenvolvidos em suas escolas não partiam das empresas e de $43,44 \%$ terem declarado, como mencionamos a pouco, que as empresas não tinham qualquer envolvimento com os projetos de EA desenvolvidos ali, o referido autor, ao apresentar os resultados da questão que buscou identificar os principais temas tratados nos projetos de EA, afirma: escolas pesquisadas são propostos pelas empresas em seus projetos de responsabilidade social e sustentabilidade: água (34,80\%), principal tema dos projetos das empresas Nova CEDAE e Ampla, e lixo e reciclagem (39,60\%), tema gerador 
do projeto Fazendo a Diferença da Indústria Comary de Bebidas. (LAMOSA, 2010, p. 125).

Embora os temas "Lixo e reciclagem" e "Água", também tenham se sobressaído em nossa pesquisa, julgamos ser precipitado creditar esta distinção as ações de responsabilidade social das empresas.

$\mathrm{Na}$ zona urbana, todos os 14 respondentes que indicaram os três principais temas tratados nos projetos educativos ambientais de suas escolas incluíram o par "Lixo e reciclagem". Dentre estes 14 respondentes apenas 2 declararam que a iniciativa dos projetos que desenvolviam partiam das empresas.

$\mathrm{Na}$ zona rural, 5 dos 9 respondentes marcaram o par "Lixo e reciclagem". Contudo, nenhum destes 5 respondentes asseverou que a iniciativa dos projetos de EA realizados em suas escolas partiam das empresas. Como então atribuir a primazia dos temas "Lixo e reciclagem" às ações de responsabilidade social dos empresários?

Com base em dois itens do questionário utilizado em nossa pesquisa daremos uma explicação diferente da que Lamosa (2010) deu para o primado dos temas "Lixo e reciclagem" e "Água".

Àqueles que respondessem afirmativamente a questão "A escola desenvolve atividades de Educação Ambiental?" pedimos que as descrevessem. Estas atividades em sua maior parte relacionavam-se aos temas: lixo, coleta seletiva e reciclagem. Dentre as mais citadas estava a arrecadação de materiais para a coleta seletiva. A dedicação a esse trabalho era tão impressionante que ao serem indagados sobre quais eram os problemas ambientais existentes na escola e em seu entorno (bairro), dois dos nossos respondentes, ignorando, por exemplo, os gravíssimos problemas socioambientais que decorrem do fato do município de Teresópolis não ter um sistema de coleta, transporte, tratamento e uma disposição final adequada dos esgotos sanitários, assinalaram a falta de lixeiras para a coleta seletiva.

Outros dois respondentes, igualmente preocupados com esta atividade, aproveitaram o espaço reservado a informações complementares, no final do questionário, para justificar o fato de suas escolas não estarem separando o lixo: [1] "A equipe diretiva entrou em contato com a Secretaria de Meio Ambiente, buscando ajuda e suporte material para a implantação da coleta seletiva do lixo e aguarda a reforma do pátio para instalação do tonel pra lixo reciclável" (Questionário n. 15). [2] "Este ano não pudemos realizar a coleta seletiva por falta de espaço para armazenar os latões de coleta". (Questionário n. 24). Porém, apesar deste impedimento, esta última escola, como tantas outras, não deixou de priorizar os temas lixo, coleta seletiva e reciclagem em suas atividades de Educação Ambiental, destacando-os através de palestras.

Inspirados pelo estudo intitulado "As publicações acadêmicas e a Educação Ambiental na Escola Básica" (TOZONI-REIS; TEIXEIRA; MAIA, 2011), também buscamos através do nosso instrumento de coletada de dados

revista brasileira educação ambiental 
identificar as fontes de informação que os professores que atuavam na rede pública municipal de ensino de Teresópolis utilizavam para sua formação em Educação Ambiental. Como no mencionado estudo (TOZONI-REIS; TEIXEIRA; MAIA, 2011), as revistas, a Internet e os jornais - assinalados por quase todos os nossos respondentes (respectivamente por 34, 33 e 34 de um total de 37) se destacaram em nossa pesquisa.

Deste modo, informados e formados por jornais e revistas, os professores da rede pública municipal de ensino de Teresópolis darão destaque nos projetos de Educação Ambiental que desenvolvem aos temas maciçamente explorados por estes veículos de comunicação social, a saber, a água e a reciclagem do lixo.

Além de ser um razoável argumento para justificar a primazia daqueles temas nas ações educativas ambientais desenvolvidas nas escolas da rede municipal de Teresópolis, esta formação em Educação Ambiental - que se faz escorada em jornais e revistas, ou seja, a partir de uma visão fragmentada, simplista e reduzida da realidade socioambiental - tende a esclarecer as origens de uma Educação Ambiental frágil e ingênua, apanhada por uma "armadilha paradigmática" (GUIMARÃES, 2011).

No tocante a "Água", Lamosa (2010) considera: "[...] principal tema dos projetos das empresas Nova CEDAE e Ampla, [...]" (LAMOSA, 2010, p. 125). Desconfiados do fato da "Ampla" - uma empresa distribuidora de energia elétrica - dar destaque a "Água" em seus projetos de responsabilidade social, avançamos deixando, entretanto, nossa dúvida em suspenso.

Em seguida perguntamos: "Algum professor de sua unidade escolar já recebeu formação em Educação Ambiental?". Dentre os 24 respondentes da zona urbana, 17 declararam que as escolas que administravam não contavam com nenhum professor com formação em EA ( $\mathrm{Na}$ zona rural, 8 de um total de 13 respondentes afirmaram o mesmo). Das 7 respostas positivas vindas da zona urbana, uma nos chamou a atenção: o CIEP "municipalizado" professor Amaury Amaral dos Santos contava com duas professoras que haviam participado de uma formação em Educação Ambiental - "Consciência Ampla Futuro"7 - promovida pela empresa "Ampla". Nesta, o principal tema abordado foi: "Conscientização sobre o uso de fontes de energia" (Questionário n. 3). Retornando a dúvida deixada em suspenso no parágrafo anterior, ressaltamos que, embora o CIEP "municipalizado" professor Amaury Amaral dos Santos tenha sido um dos 4 estabelecimentos de ensino em um universo de 37 instituições pesquisadas onde a iniciativa da realização de projetos de EA

\footnotetext{
7 De acordo com o sítio da empresa "Ampla" na Internet: "O Consciência Ampla Futuro forma jovens multiplicadores nas escolas para disseminar a importância do consumo consciente da energia elétrica e dos recursos naturais. Desde 2004, através de uma parceria da Ampla e professores capacitados, são realizadas atividades como oficinas, jogos e teatros ao longo de todo ano letivo". Disponível em: $<$ https://www.ampla.com/ampla-e-a-sociedade/programas-e-projetos/consci\%C3\%AAnciaampla/consci\%C3\%AAncia-ampla-futuro.aspx>. Acesso em: 15 jan. 2014.
} 
partia das empresas ${ }^{8}$, a "Água" não figurou entre os três principais temas abordados ali. Ora, se a "Água" fosse, conforme afirma Lamosa (2010, p. 125) o principal tema dos projetos da empresa "Ampla", este tema não seria enfatizado nos cursos de formação de educadores ambientais promovidos pela mesma empresa e provavelmente destacado pelos professores em suas ações de Educação Ambiental nas escolas?

Apesar do expressivo número de estabelecimentos de ensino da rede municipal que não contavam com nenhum professor com formação em Educação Ambiental (25 em um universo de 37), menos da metade dos respondentes (15 de 35 ) indicou a "falta de formação inicial e continuada dos professores" como uma das principais dificuldades enfrentadas para 0 desenvolvimento da Educação Ambiental na escola. Ao contrário, para eles, a maior oposição à Educação Ambiental vinha da "precariedade de recursos materiais (transporte, equipamentos)" ${ }^{\prime \prime}$.

Tal percepção expressa uma concepção conservadora de Educação Ambiental (LAYRARGUES; LIMA, 2011), que se traduz em "visitas a natureza"10, no plantio de mudas, entre outras ações educativas ambientais, que, sem dúvida, dependem do transporte que, conforme assinalou a maior parte dos respondentes, era precário.

Esta concepção conservadora de Educação Ambiental (LAYRARGUES; LIMA, 2011) apoia-se em uma compreensão reducionista do conceito de "meio ambiente", que o confunde com a "natureza" (nota-se aqui a ideia de uma "natureza" desumanizada). Neste meio ambiente sem gente dissociação entre o social e o ambiental - a sociedade vê-se afastada da natureza (não por acaso nossos respondentes reclamavam das dificuldades do desenvolvimento da Educação Ambiental, pois como fazê-la sem o ônibus escolar?). Por conseguinte, os problemas ambientais e a crise que deles decorrem serão identificados "[...] como aqueles que envolvem as florestas, as espécies silvestres e os ecossistemas naturais, desvinculados da sociedade e da cultura" (LIMA, 2011, p. 40).

Em meio à falta de um hospital público municipal em Teresópolis, ao reduzido número de vagas nas poucas creches municipais, a precariedade do transporte público, a inexistência de um sistema de coleta, transporte, tratamento e disposição final adequada dos esgotos sanitários, ao uso indiscriminado e abusivo de agrotóxicos na zona rural do município, a ocupação das áreas de risco, ao aumento da pobreza etc., continuaremos levando a efeito uma Educação Ambiental conservadora (LAYRARGUES; LIMA, 2011)?

\footnotetext{
${ }^{8}$ Assim como outros 4 estabelecimentos de ensino da rede a mesma escola também declarou que seus projetos de educação ambiental envolviam as empresas.

925 dos 35 respondentes assinalaram esta opção.

10 Refiro-me as idas as Unidades de Conservação de Proteção Integral situadas no município de Teresópolis. 
Por outro lado, a ênfase dos projetos de Educação Ambiental na questão do lixo, coleta seletiva e reciclagem preocupam-nos igualmente.

Desenvolvidos na maior parte dos casos através de uma competição entre escolas e/ou turmas e/ou alunos - vence quem traz mais lixo (material reciclável) -, tais projetos dão a falsa impressão de que os problemas ambientais - entendidos neste caso como efeitos colaterais do crescimento econômico - podem ser solucionados no interior do próprio sistema capitalista ${ }^{11}$.

Em meio ao consumismo, a obsolescência programada, a descartabilidade entre outros males, uma Educação Ambiental pragmática (LAYRARGUES; LIMA, 2011) - voltada, em função da reciclagem, para a coleta seletiva de materiais recicláveis (ênfase em uma solução técnica) - que focaliza apenas uma consequência pontual da questão do lixo, é o bastante?

\section{Conclusões}

Ante ao "engavetamento" da Política Municipal de Educação Ambiental (TERESÓPOLIS, 2011), a partir de nossa investigação nas escolas, constatamos que o direito à Educação Ambiental (BRASIL, 1999), dever do poder público (BRASIL, 1999) é em Teresópolis um privilégio de poucos, uma questão de sorte ou azar dos alunos que poderão ou não vir a ter acesso à Educação Ambiental a depender - como revelaram alguns dos principais resultados de nossa pesquisa - das iniciativas individuais dos profissionais que atuam em suas escolas, e/ou, mais raramente, da "responsabilidade social" das empresas.

Sobre a Educação Ambiental que se faz na rede pública municipal de Teresópolis, destacamos, por um lado, a marcante presença de uma concepção conservadora de Educação Ambiental (LAYRARGUES; LIMA, 2011), que se traduz em "visitas a natureza", no plantio de mudas, entre outras ações educativas ambientais. Por outro lado, a impressionante dedicação ao trabalho de arrecadação de materiais para a coleta seletiva - uma das principais atividades de Educação Ambiental desenvolvidas pelas escolas da rede publica municipal de Teresópolis - evidencia o predomínio de uma Educação Ambiental pragmática (LAYRARGUES; LIMA, 2011) focalizada em uma consequência pontual da questão do lixo.

A partir destas conclusões indagamos: em meio as enormes mazelas socioambientais de Teresópolis evidenciadas pelo maior desastre "natural" da história do país, que Educação Ambiental necessitamos fazer?

Por certo as muitas respostas possíveis estão relacionadas aos diversos objetivos almejados. Assim sendo, com o quê temos sonhado? Com indivíduos sensíveis para o convívio com a natureza? Sonhamos com consumidores dispostos a fazerem cada um a sua parte em busca de um 
desenvolvimento capaz de preservar o atual modo de produzir e acumular riquezas? Ou temos sonhado com outra sociedade, uma sociedade sustentável, igualitária, justa e feliz?

\section{Referências}

BRASIL. Lei n. 9.795, de 27 de abril de 1999. Dispõe sobre Educação Ambiental e institui a Política Nacional de Educação Ambiental, e dá outras providências. Diário Oficial [da] União, Brasília, 28 abr. 1999.

GUIMARÃES, M. A Formação de Educadores Ambientais. $8^{\underline{a}}$ ed. Campinas: Papirus, 2011.

LAMOSA, R.A.C. A Educação Ambiental o novo padrão de sociabilidade do capital: um estudo nas escolas de Teresópolis (RJ). 2010. 176f. Dissertação (Mestrado em Educação) - Curso de Pós-Graduação em Educação, Universidade Federal do Rio de Janeiro.

LAYRARGUES, PP.; LIMA, G.F.C. Mapeando as macro-tendências políticopedagógicas da Educação Ambiental contemporânea no Brasil. In: ENCONTRO PESQUISA EM EDUCAÇÃO AMBIENTAL, VI, 2011, Ribeirão Preto. Anais... Ribeirão Preto: EPEA, 2011. 1 CD-ROM, p. 1-15.

LIMA, G.F.C. Os antecedentes da Educação Ambiental. In: LIMA, G.F. Educação Ambiental no Brasil: formação, identidades e desafios. Campinas: Papirus, 2011. p. 25-97.

TERESÓPOLIS. Lei n. 3017, de 01 de junho de 2011. Institui a Política Municipal de Educação Ambiental - PMEA e cria o Grupo de Trabalho de Educação Ambiental - GTEA. Diário Oficial [do] Município de Teresópolis, Teresópolis, 03 jun. 2011.

TOZONI-REIS, M.F.C.; TEIXEIRA, L.A.; MAIA, J.S.S. As publicações acadêmicas e a Educação Ambiental na Escola Básica. In: REUNIÃO ANUAL DA ANPEd, 34a., 2011, Natal. Anais... Natal, 2011. p. 1-11. Disponível em: <http://www.anped.org.br/app/webroot/34reuniao/images/trabalhos/GT22/GT22 -257\%20int.pdf>. Acesso em: 10 out. 2013.

TRAJBER, R;; MENDONÇA, P.R. (Orgs.). Educação na diversidade: o que fazem as escolas que dizem que fazem Educação Ambiental . Brasília: Secretaria de Educação Continuada, Alfabetização e Diversidade. Ministério da Educação, 2006. 